\title{
Across the Pons and to the Milky Way: Where Are the Neuroradiology Publications?
}

$\mathbf{F}$ ive years ago, we published an article in the American Journal of Neuroradiology that demonstrated that publications describing imaging features of various uncommon CNS diseases predominate in the clinical, rather than radiology, literature. ${ }^{1}$ Short, simple, and purely an enumeration of journal articles, Impact Factors, and radiologist authorship, our article was a practical wake-up call to authors, reviewers, and publishers of radiologic content that remains relevant today. Specifically, there continue to be frequent reports of novel neuroradiology findings of important conditions, even in instances in which such imaging findings are the primary purpose, embedded within the nonradiology literature. While a clinician target audience is understandable in many cases in which the impact of such findings on clinical care is paramount, even in these instances, acknowledged neuroradiology interpretation of the images and neuroradiology authorship can be lacking. ${ }^{1}$

For example, consider just 1 disease process: progressive multifocal leukoencephalopathy. A few months ago, an interesting case report described the "punctate MR imaging pattern" in the setting of systemic lupus erythematosus-associated progressive multifocal leukoencephalopathy. ${ }^{2}$ This case report is found in a clinical journal with authors affiliated with neurology, pathology, and virology departments. Various other recently reported imaging patterns or "signs" of progressive multifocal leukoencephalopathy discussed within this article or related articles include the "across the pons sign," "inverse trident sign," "barbell sign," "laminar cortical hypointensity" and other findings on susceptibility-weighted imaging, and the "Milky Way" appearance. ${ }^{2-8} \mathrm{Al}-$ though some of these other articles on this topic did include representation of radiologists in the authorship list, only the "barbell sign" was found to be primarily described in a radiology journal. To research further, I performed a PubMed search from January 1, 2017, to January 1, 2019, with the following criteria: (MR imaging OR MR imaging) AND (PML or progressive multifocal leukoencephalopathy). This search resulted in 96 publications, 6 (6\%) of which were published in radiology journals.

Clinicians may be exposed to (and, indeed, may independently author) articles describing neuroradiology features and

http://dx.doi.org/10.3174/ajnr.A6039 signs that could evade members of the neuroradiology community. Although the reasons for this phenomenon of radiology descriptions appearing in clinical journals are multifactorial, $1 \mathrm{fac}-$ tor is that a high percentage of these signs are found in case reports, which are still published in some clinical journals but not as frequently in radiology journals. Other factors may include the larger number of clinical, compared with radiology, journals or perhaps articles by highly subspecialized clinicians who have a preference for publishing in a clinical journal.

One could submit that in the era of electronic article searches, the precise journal classification is less relevant than it was in the past. However, it is not always easy to find these described findings embedded in clinical journals during a busy shift, and neuroradiologists may not be prompted to search for them if they are unaware of their existence. In addition, due to blinding of the peer-review process, it is not known how frequently radiologists are invited to participate in the adjudication of such articles before publication in clinical journals, potentially contributing to variability in the utility and accuracy of reported findings. Five years after our study demonstrated a preponderance of neuroradiology-focused literature published in clinical journals, it appears as though this practice persists. It is incumbent on the neuroradiologist to be cognizant of alternate sources of information and to challenge and/or validate findings in the peer-reviewed radiology literature. Finally, wherever possible, it is important that neuroradiologists be visible within multidisciplinary care teams and engaged in clinical research. Such participation may help raise the quality of reporting of radiologic findings and ensure that they are represented in the appropriate specialty literature sources.

\section{REFERENCES}

1. Lehman VT, Doolittle DA, Hunt $\mathrm{CH}$, et al. Intracranial imaging of uncommon diseases is more frequently reported in clinical publications than in radiology publications. AJNR Am J Neuroradiol 2014;35: 45-48 CrossRef Medline

2. Ishii J, Shishido-Hara Y, Kawamota M, et al. A punctate magnetic resonance imaging pattern in a patient with systemic lupus erythematosus is an early sign of progressive multifocal leukoencephalopathy: a clinicopathologic study. Intern Med 2018; 57:2727-34 CrossRef Medline

3. Hodel J, Darchis C, Outteryck O, et al. Punctate pattern: a promising 
imaging biomarker for the diagnosis of natalizumab-associated PML. Neurology 2016;86:1516-23 CrossRef Medline

4. Jain RS, Nagpal S, Tejwani S. 'Hot-cross bun' and 'inverse trident sign' in progressive multifocal leukoencephalopathy with HIV seropositivity. Neurol India 2014;62:341-42 CrossRef Medline

5. Sinnecker T, Othman J, Kühl M, et al. 7T MRI in natalizumab-associated PML and ongoing MS activity: a case study. Neurol Neuroimmunol Neuroinflamm 2015;2:e171 CrossRef Medline

6. Bezuidenhout AF, Andronikou S, Ackermann C, et al. "Barbell Sign": a diagnostic imaging finding in progressive multifocal leukoencephalopathy. J Comput Assist Tomogr 2018;42:527-30 CrossRef Medline

7. Pontillo G, Cocozza S, Lanzillo R, et al. Brain susceptibility changes in a patient with natalizumab-related progressive multifocal leukoencephalopathy: a longitudinal quantitative susceptibility mapping and relaxometry study. Front Neurol 2017;8:294 CrossRef Medline

8. Papadimitropoulos GN, Lachanis S, Zompola C, et al. Laminar cortical hypointensities in susceptibility-weighted imaging in a case of progressive multifocal leukoencephalopathy. J Clin Neurol 2017;13: 201-02 CrossRef Medline

(1) V.T. Lehman

Department of Radiology

Mayo Clinic College of Graduate Medical Education

Rochester, Minnesota 